\title{
Impacts of resistance exercises intervention on thyroid hormone and thyroid stimulating hormone serum concentration level in school children with intellectual disabilities
}

\author{
Kefelegn Zenebe ${ }^{1}, \odot$ Kesatie Legesse ${ }^{2}, \odot$ Soumitra Mondal ${ }^{2}, \odot$ Mahmud Abdulkader ${ }^{3}$, \\ Kidanie Aragaw Alemu ${ }^{4}$
}

${ }^{1}$ Department of Sport Science, Wollo University, Dessie, Ethiopia. ${ }^{2}$ Department of Sport Science, Mekelle University, Mekelle, Ethiopia. ${ }^{3}$ Institute of Medical Microbiology and Immunology, Mekelle University, Mekelle, Ethiopia. ${ }^{4}$ Department of Statistics, WolloUniversity, Dessie, Ethiopia.

\begin{abstract}
The effect of resistance exercise on muscular strength with the influence of growth hormone is well known. However, there is little information about its underlying effect on thyroid hormones (T3 \& T4) and thyroid-stimulating hormones. Specifically, no research has been done on the effect of a resistance exercise intervention on thyroid hormone and thyroid-stimulating hormone serum concentration level among school children with intellectual disability in Ethiopian. The objective of this study was to investigate the effect of sixteen-week of a resistance exercise intervention on serum concentration level of thyroid hormones (T3 \& T4) and thyroid-stimulating hormone (TSH) in school children with intellectual disabilities. In this study, eighteen school children with intellectual disabilities participated. The participants' serum concentration level of triiodothyronine (T3), thyroxin (T4) and TSH were measured before and after a sixteen-week resistance exercise intervention and determined using quantitative determination of T3, T4, and TSH respectively. Paired ttest was used to analyze the pre-test and post-test data of thyroid hormones (T3 and T4) and TSH of the study. Aftersixteen weekof resistance exercise intervention, a significant mean score change was observed in the serum concentration level of thyroid hormones $(p<0.05)$ in T3 $(p=0.038), T 4(p=0.017)$ and TSH $(p=0.018)$. Our finding revealed that resistance exercise affects the serum concentration level of thyroid hormones and thyroidstimulating hormones in school children with intellectual disabilities.
\end{abstract}

Keywords. Intellectual disabilities, resistance exercise, tetraiodothyronine, thyroid stimulating hormones, triiodothyronine.

\section{Introduction}

Intellectual disability (ID) is characterized by a significant impairments of cognition and development due to abnormalities in the structure and function of brain and the worldwide prevalence of individuals with ID is 1-3 \% (Iqbal et al., 2016). It is considered as the most prevalent of other developmental disabilities (Morin, 2012) and the largest disability grouping in Africa (Mckenzie et al., 2013). The profile of the magnitude of person with intellectual disabilities in Ethiopia is $2.4 \%$ (Tirusew, 2005) and caused by malnutrition and famine in Ethiopia (Wines, 2006). In North West Ethiopia the prevalence of ID is $10.3 \%$ among the total individuals with disability (Fitaw \& Boersma, 2006).

ID is a serious problem in the entire world ( $\mathrm{WHO}$, 1996) and characterized by having motor difficulties and limitations expressed in the performance of sports skills (WHO, 2011) influencing cognitive, social or emotional areas of functioning, therefore, to whatever extent a special physical activity and adapted to be able to move forward and towards independent living (Bechara \& Grosub, 2016). These 
difficulties can influence cognitive, social and emotional areas of functioning and has led their families to suffer in economic and social disadvantages than those without disabilities (Jenkins \& Rigg, 2003) and have a lack of perceived social acceptance (Jahoda et al., 2008). Discrimination, access and lack of work place accommodation to justice and education are the challenges of ID in Africa (Njenga, 2009).

The socio economic condition of individuals with ID in Ethiopia in terms of social life, education, occupation, and economic level is generally poor (Ayele, 2016) and parents face emotional, social economic and material challenges while raising their children with ID (Weldeab \& Opdal, 2007). Considering the factors affecting the attainments of the goals of a country in relation to create productive human power, the most important approach might be identifying, the parts of a society that needs special treatment in order to develop their productivity at large. Therefore, we identified school children with ID that require more attention in social and economic advantages are to be optimized and lead independent way of life.

Thyroid hormone (T3 and T4) have many physiological activities that makes them essential for normal behavioral, intellectual and neurological development (Rivas \& Naranjo, 2007). It controls the conversion of glucose to chemical energy (Marieb \& Hoehn, 2007) which is essential for normal growth and developments (Brent, 2012)and regulate metabolism and has led to several new therapeutic targets for metabolic disorder (Mullur et al., 2014). Although, thyroid stimulating hormone (TSH) stimulates the mechanism of all body cells and increase carbohydrate and fat breakdown energy mechanisms (McArdle et al., 2010). Thyroid hormones (T3 and T4) are critically important and accelerate growth and stimulate activities in central nervous systems (DeRuiter, 2001). This is why thyroid hormones have an exciter effect on the central nervous system and increase the rapidity of cerebration but also often dissociation. However lack and deficiencies of these thyroid hormones decrease these function (Guyton \& Hall, 2013).

Reduction in thyroid hormones during brain maturation yields molecular, morphological and functional alterations in the central nervous system such as the cerebral cortex, hippocampus and cerebellum and are indicated to cause impaired brain maturation and intellectual deficits (Lee et al., 2003). These deficiencies can negatively affect cognitive functioning and the decreased cognitive function in turn might be a determent to achieve high standards in academics (Somashekar et al., 2014).

Individuals with ID performed at a significantly lower level in abdominal strength/endurance fitness qualities, static balance and manual dexterity when they are compared to nondisabled equivalent peers in early adolescence ages (Lahtinen et al., 2007). When a muscle of a specific body is weak poor posture can result and lack of strength in the abdominal muscles related to poor posture can be improved by executing regular progressive resistance exercise (Corbin et al., 2000).

The duration, intensity and type of training modulate hormone fluctuation (Lencuet al., 2016). An increase in Thyroid hormones (T3 and T4) and a decrease in thyroid stimulating hormone in serum concentration level depend on the intensity of exercise and the specific characteristics of an individual (Ciloglu et al., 2005). Therefore, regular physical exercise at moderate intensity can increase the serum concentration level of $\mathrm{T} 3$ and $\mathrm{T} 4$ and decrease serum concentration level of TSH (Bansal et al., 2015).

Resistance exercise could have an impact on endocrine hormonal changes responses (Cissik, 2001). Hormonal mechanisms appear to be involved with both short-term homeostatic control and longterm cellular adaptations. A variety of resistance exercise protocols result in increases in peripheral hormonal concentrations. It appears that single factor variables such as the intensity of exercise and amount of muscle mass utilized in the exercise 
protocol are important determinants of hormonal responses (Kraemer, 1988). Changes in strength and hormonal concentrations depend on the characteristics of the resistance training program, with the most important being exercise intensity and volume (Tsolakis \& Bogdanis, 2007). Thus; resistance training have the capability to alter thyroid function but the influence of these alterations remains speculative (Kraemer \& Ratamess, 2005).

Resistance training in children may result in an increase in hormones influencing anabolic activity and has in physiological performance and trainability even at the early stages of poverty (Tsolakis \& Bogdanis, 2007). Its effect on thyroid hormone change responses would be related to an improvement of body composition (Mehravar, 2018). Skeletal muscles maintain posture and enable movement by converting chemical energy. Thyroid hormones (T3 and T4) participate in contractile function, metabolic process, myogenesis and regeneration of skeletal muscles and have a role in the sarcopenic process (Bloise et al., 2018). Thyroid hormones are important in regulations of total energy requirements leading to influence body composition which is directly related to weight gain and loss (Corbetta et al., 1997).

Studying growth hormones regulation and physiological effects is difficult without taking thyroid function into account. Both growth hormone and thyroid hormones involved in growth. Thyroid hormone stimulates the production of growth factors and affects growth hormone and somatomedin production and their tissue activity (Cabello \& Wrutniak, 1989). Thyroid hormone exerts a permissive effect upon the anabolic and metabolic effects of growth hormone, and increases pituitary synthesis of this protein hormone. Growth hormone depresses the secretion of thyroid stimulating hormones and the thyroid hormones and increases the peripheral conversion of thyroxin to triiodothyronine (Root et al., 1986).
In our previous study, we reported that aerobic exercise can affect the serum concentration level of T3, T4 and TSH (Zenebe et al., 2019; Altaye et al., 2019). However, specifically no research has been done on the effect of resistance exercise intervention on thyroid hormones and thyroid stimulating hormone serum concentration level among school children with intellectual disability in Ethiopian. Therefore, the result of this study may be important for physical educators, special need educators, exercise physiologists, sport psychologist and individuals with ID and their families while planning the training protocol for children with ID.

\section{Methods}

\section{Study Setting and Ethical Approval}

Ethical approval was obtained from institutional Research Ethics Review Committee of Mekelle University with Ref. ERC 1078/2017 dated 26/06/2017conformed to the 1975 Declaration of Helsinki. A written consent to participate in the study was obtained from study participants. In addition a written assent to participate in the study was obtained from the guardians of the study participants. The subject guardians were very enthusiastic and cooperatives throughout the training program. There was no study participants and public involvement in recruitment of the study subjects, selecting and planning of exercise, designing the training protocol and outcome measures to conduct of this study.

This study was carried out in Dessie and Kombolcha. Dessie is one of the special city administrative zone of Amhara regions and served as the capital city of South Wollo Administration Zone whereas; Kombolcha is a district and one of the industrial cities of Ethiopia. Dessie and Kombolcha 475 and $500 \mathrm{~km}$ far away from (Bahirdar), the capital of the region and $401 \mathrm{~km}$ and $375 \mathrm{~km}$ far from Addis Ababa, the capital city of Ethiopia. 


\section{Sampling Technique and Study Participants}

Pre-test and post -test design on the effects of sixteen week of resistance exercise intervention on T3 \& T4 and TSH serum concentration level of school children with ID in three schools of DessieKombolcha was employed. Sample schools and the study participants were taken by purposive sampling techniques.

The participants of this study were free from epilepsy and autism disorders. The whole numbers of these participants were eighteen. After explanation of the purposes of the study and the privacy of information for the participants and their parents/guardians were completely satisfied to cooperate in the participation of the study. When inviting the experimental group to participate in the process of orientation about how to conduct resistance exercises before the beginning of the main exercise protocol, the parents/guardians of the study participants committed that these study participants can participate in the sixteen week resistance exercise intervention process of this study. Then after raw data about T3 \& T4 and TSH were obtained. The study participants thyroid hormones and thyroid stimulating hormones were determined using enzyme linked immunosorbant assay (ELISA) method.

\section{Training Protocol}

The training program (Table 1) consisted of sixteen week of progressive intensity resistance exercises and conducted after receiving the parental consent.
These exercises were performed three sessions a week and each session took forty five minutes. These are ten minutes of warm-up exercises, fifteen to thirty minutes of main resistance exercise intervention and five minutes cool-down exercises.

\section{Data Sources and Proceduresof Data Collections}

Primary data was used for the analysis. In order to measure the plasma level of T3 \& T4 and TSH. The blood samples were drawn from individuals 48 hours before the first training session and after sixteen week training 48 hours after the last training session. Samples of Blood specimen were collected by qualified laboratory technicians in the sitting position. Six milliliters of venous blood were taken from each study participant's vein in each pre and post-tests. The blood samples were drawn into tubes containing anticoagulant and carried to the laboratory by cool box. In the laboratory all blood samples were preserved in the frozen condition at $20^{\circ}$ until analysis process. All variables were measured using the Auto Bio laboratory kits by the enzyme linked immunosorbant assay (ELISA) method. After sixteen week of exercise intervention test results were computed using mean and standard deviation. In this study paired t- test was used to compare the pre-test and post-test data. The significance level was considered at $p<0.05$.

\section{Data Analysis}

Data were entered to an excel spread sheet and cleaned. Statistical analysis was performed using Statistical Package for Social Science (SPSS) version

Table 1

Training protocols of resistance exercise intervention.

\begin{tabular}{lccccl}
\hline Phase & Weeks & Frequency & Repetition & Time/Minutes & Type of exercise \\
\hline Phase-1 & $1-4$ & 3 & $3-5$ & $15-18$ & Back bridge, Wall seat, Triceps press, \\
Phase-2 & $5-8$ & 3 & $5-8$ & $19-22$ & Overhead, Arm press, Leg press in doorway, \\
Phase-3 & $9-12$ & 3 & $9-12$ & $23-26$ & Trunk lift, Bent knee push up, Side leg raises, \\
Phase-4 & $13-16$ & 3 & $13-16$ & $27-30$ & Side Bridge \\
\hline
\end{tabular}

Source $=$ Adapted from ACSM, 2014 
20. Test results were computed using mean and standard deviation. In this study paired $t$ - test was used to compare the pre-test and post-test of the experimental group on the effects sixteen week resistance exercise intervention on $\mathrm{T} 3 \& \mathrm{~T} 4$ and $\mathrm{TSH}$ serum concentration level in school children with ID. The significance level was considered at $p<0.05$.

\section{Results}

In this study, 18 students with ID were studied. Table 2 shows the mean and standard deviation of age, height and mass of the students with ID.

Table 3 presents the mean score results at $(p<$ $0.05)$ between the pre-test and post-test of the group treated with resistanceexercise in $\mathrm{T} 3(\mathrm{p}=0.038), \mathrm{T} 4$ $(\mathrm{p}=0.017)$ and TSH $(\mathrm{p}=0.018)$.

\section{Table 2}

Demographic characteristics of resistance exercise and control group's adolescents with ID $(n=18)$.

\begin{tabular}{lc}
\hline Variables & $\mathrm{M} \pm \mathrm{SD}$ \\
\hline Age (years) & $14.25 \pm 1.14$ \\
Height (m) & $1.51 \pm 0.04$ \\
Mass (kg) & $49.24 \pm 5.89$ \\
\hline
\end{tabular}

M: Mean, SD: Standard deviation

Table 3

Paired t-test analysis on the effect of resistance exercise on thyroid and thyroid stimulating hormones variables serum concentration level of adolescents ID ( $\mathrm{n}=18)$.

\begin{tabular}{llcccc}
\hline Variables & Tests & $\mathrm{M} \pm \mathrm{SD}$ & $\mathrm{t}$ & $\mathrm{df}$ & $p$ \\
\hline T3 & Pre-test & $1.47 \pm .171$ & 2.251 & 17 & $0.038^{*}$ \\
& Post-test & $1.5 \pm .18$ & & & \\
T4 & Pre-test & $6.51 \pm 1.14$ & 2.652 & 17 & $0.017^{*}$ \\
& Post-test & $6.94 \pm 1.03$ & & & \\
TSH & Pre-test & $1.42 \pm .35$ & -2.626 & 17 & $0.018^{*}$ \\
& Post-test & $1.34 \pm .32$ & & & \\
\hline
\end{tabular}

T3: Triiodothyronine, T4: Tetraiodothyronine, TSH: Thyroid stimulating hormone, * The mean difference is significant at .05.

\section{Discussion}

The main objective of this study was to investigate the effects of sixteen week resistance exercise on serum concentration level of thyroid hormones and thyroid stimulating hormone in school children with ID. Our sixteen week resistance exercise intervention showed statistically a significant increase $(p<0.05)$ in T3 $(p=0.038)$ and T4 $(p=0.017)$ serum concentration level and decrease in TSH serum concentration level $(p=0.018)$ after the resistance exercise intervention when compared with before intervention.

The result of this study was inconsistent with the previous studies (Cissik, 2001; Kraemer, 1988; Kraemer \& Ratamess, 2005; Rahimi et al., 2013) that reported resistance exercise alone had not shown a significant mean score change in the serum concentration of T3, T4 and TSH. However, in this study these changes in the concentration of T3, T4 and TSH might be due to the specific physical and physiological characteristics of adolescents with ID. They have lower abdominal strength (Axuter et al., 1997), over weight problems (Rimmer et al., 2004). In general (Fahey et al., 2005; Stavres et al., 2018) confirmed that all these poor qualities can be improved by executing resistance exercises. For example (Fahey et al., 2005) reported that besides to increasing muscular strength; resistance exercises plays a great role in order to improve body composition, increase metabolism, delivery of oxygen and nutrients to each muscle cells and plays a great role to increase lean muscle mass and can reduce the amount of fat mass.

Resistance exercise can improve abdominal muscle strength and health management in people with ID (Son \& Jeon 2017). The upper and lower body muscles (Smail \& Horvat, 2009), strengthen cranio-cervical flexor muscles that help to maintain the neck and shoulder posture (Lee et al., 2013) promotes muscle fitness that permits an 
efficient and effective movement contributes to ease and economy of muscle effort, successful performance and can lower susceptibility to some types of injuries (Corbin et al., 2004) and balance developing exercises training and postural exercises improves functional level of individuals with ID (Kubilay et al., 2011).

For all this reasons the researchers believe that resistance exercise intervention could modulate and modify the thyroid response depending on several complex inter related reasons. Therefore resistance exercise which is designed based on its unique nature in a variety of exercise with a progressive overload with the consideration of number of sets under the supervision personal trainers leads to have a therapeutic influence to modulate thyroid and thyroid stimulating hormones and parents can use it as a treatment to improve the physiological causes of cognition impairment' and life style of their family with ID. These movement treatment effects can motivate and encourage school children with ID to actively participate in regular resistance exercise training program in order to enhance their capability in the participation of the overall educational, social and economical activities instead of leading sedentary way of life.

\section{Conclusion}

Our finding revealed that sixteen-weekprogressive intensity of resistance exercise had shown a significance change in the serum concentration level of thyroid hormones (T3, T4) and thyroid stimulating hormone (TSH) in school children with ID.

\section{Acknowledgment}

The authors would like to acknowledge Mekelle University, Wollo University, study subjects and their parents, trainer coaches who helped us in this study are greatly appreciated.

\section{Conflict of interest}

We declare that we don't have any conflicts of interest relevant to the content of this study.

\section{References}

Altaye, Z.K., Soumitra M., legesse, K., \& Abdulkader, M. (2019). Effects of aerobic exercise on thyroid hormonal change responses among adolescents with intellectual disabilities. BMJ Open Sport E Exercise Medicine, 5(1), e000524.

Axuter, D., Pyfer, J., \& Huetting, C. (1997). Principles and methods of adapted physical education and recreation. (eds), $8^{\text {th }}$ Edition, St. Louis, MO: Mosby Year Book.

Ayele, T. (2016). The prevalence and socio-economic condition of persons with disabilities in Hosanna Town. Doctoral dissertation, Addis Ababa University, Ethiopia.

Bansal, A., Kaushik, A., Singh, C.M., Sharma, V., \& Singh, H. (2015). The effect of regular physical exercise on the thyroid function of treated hypothyroid patients: An interventional study at a tertiary care center in Bastar region of India. Archives of Medicine and Health Sciences, 3(2), 244.

Bechara, I., \& Grosub, E.F. (2016). Physical activity and intellectual disabilities. The European Proceedings of Social and Behavioural Sciences, 18, 225-234.

Bloise, F.F., Oliveira, T.S., Cordeiro, A., \& OrtigaCarvalho, T.M. (2018). Thyroid hormones play role in sarcopenia and myopathies. Frontiers in Physiology, 9, 560.

Brent, G.A. (2012). Mechanisms of thyroid hormone action. The Journal of Clinical Investigation, 122(9), 30353043.

Cabello, G., \& Wrutniak, C. (1989). Thyroid hormone and growth: relationships with growth hormone effects and regulation. Reproduction Nutrition Development, 29(4), 387-402.

Ciloglu, F., Peker, I., Pehlivan, A., Karacabey, K., İlhan, N., Saygin, O., \& Ozmerdivenli, R. (2005). Exercise intensity and its effects on thyroid hormones. Neuroendocrinology Letters, 26(6), 830-834. 
Cissik, J.M. (2001). The basics of strength training. In: Duhon, B. (ed.), Benefits of Strength Training. $2^{\text {nd }}$ edition, New York, NY: McGraw-Hills.

Corbetta, S., Englaro, P., Giambona, S., Persani, L., Blum, W. F., \& Beck-Peccoz, P. (1997). Lack of effects of circulating thyroid hormone levels on serum leptin concentrations. European Journal of Endocrinology, 137(6), 659-663.

Corbin, C.B., Lindsey, R., \& Welk, G. (2000). Concepts of physical fitness. Active Life Styles for Wellness. In: Malinee V. \& Musal T.R. (eds), Cardiovascular fitness. $10^{\text {th }}$ Edition, New York, NY: McGraw-Hill.

DeRuiter, J. (2001). Thyroid hormone tutorial: the thyroid and thyroid hormones. Endocrine Pharmacotherapy Module: Thyroid Section, Summer, 2002, 5260.

Fahey, D.H., Insel, P.M., \& Roth, W.T. (2005). Fit and well: Core concepts and labs in physical fitness and wellness. In: Barret, N.R., Price, K. \& Bright, A. (ed), $6^{\text {th }}$ edition, New York, NY: McGraw-Hill.

Fitaw, Y., \& Boersma, J.M. (2006). Prevalence and impact of disability in north-western Ethiopia. Disability and Rehabilitation, 28(15), 949-953.

Guyton, A.C., \& Hall, J.E. (2013). Text book of medical physiology. In: Vaz, M., Kurpad, A. \& Raj, T. (ed ). India: Elsevier Inc.

Iqbal, M., Baig, M.A., Bhinder, M.A., \& Zahoor, M.Y. (2016). Factors causing mental retardation. Asian Journal of Natural and Applied Science, 5(3), 28-37.

Jahoda, A., Kemp, J., Riddell, S., \& Banks, P. (2008). Feelings about work: A review of the socio-emotional impact of supported employment on people with intellectual disabilities. Journal of Applied Research in Intellectual Disabilities, 21(1), 1-18.

Jenkins, S.P., \& Rigg, J.A. (2003). Disability and disadvantage: Selection, onset and duration effects. CASEpaper 74. London: London School of Economics.

Kraemer, W.J., \& Ratamess, N.A. (2005). Hormonal responses and adaptations to resistance exercise and training. Sports Med, 35(4); 339-361.

Kraemer, W.J. (1988). Endocrine responses to resistance exercise. Med Sci Sport Exerc, 20 (5), 52 -7.

Kubilay, N.S., Yildirim, Y., Kara, B., \& Harutoglu Akdur, H. (2011). Effect of balance training and posture exercises on functional level in mental retardation. Fizyoterapi Rehabilitasyon, 22(2), 55-64.

Lahtinen, U., Rintala, P., \& Malin, A. (2007). Physical performance of individuals with intellectual disability: A 30-year follow-up. Adapted Physical Activity Quarterly, 24(2), 125-143.

Lee, M.H., Park, S.J., \& Kim, J.S. (2013). Effects of neck exercise on high-school students' neck-shoulder posture. Journal of Physical Therapy Science, 25(5), 571574 .

Lee, P.R., Brady, D., \& Koenig, J.I. (2003). Thyroid hormone regulation of N-methyl-D-aspartic acid receptor subunit mRNA expression in adult brain. Journal of Neuroendocrinology, 15(1), 87-92.

Lencu, C., Nicula, R., \& Lotrean, M.R. (2016). Hormonal response to physical exercise. Palestrica of the Third Millennium - Civilization and Sport, 17(1), 56-60.

Marieb, E.N., \& Hoehn, K. (2007). Human anatomy \& physiology. Pearson Education Inc.

McArdle, W.D., Katch, F.I., \& Katch, V.L. (2010). Exercise physiology: nutrition, energy, and human performance. Philadelphia, PA: Lippincott Williams \& Wilkins.

Mckenzie, J.A., McConkey, R., \& Adnams, C. (2013). Intellectual disability in Africa: Implications for research and service development. Disability and Rehabilitation, 35(20), 1750-1755.

Mehravar, M.R. (2018). The effect of eight-week Pilates exercise on the thyroid function in sedentary women. Journal of Physical Activity and Hormones, 2(2), 29-42.

Morin, D., Mérineau-Côté, J., Ouellette-Kuntz, H., Tassé, M. J., \& Kerr, M. (2012). A comparison of the prevalence of chronic disease among people with and without intellectual disability. American Journal on Intellectual and Developmental Disabilities, 117(6), 455463.

Mullur, R., Liu, Y.Y., \& Brent, G.A. (2014). Thyroid hormone regulation of metabolism. Physiological Reviews, 94(2), 355-382.

Njenga, F. (2009). Perspectives of intellectual disability in Africa: epidemiology and policy services for children and adults. Current Opinion in Psychiatry, 22(5), 457461. 
Rahimi, E., Zadeh, M.Y., \& Boostani, A.M. (2013). The effect of resistance training on thyroid hormones. European Journal of Experimental Biology, 3(2), 443-447.

Rimmer, J.H., Heller, T., Wang, E. \& Valerio, I. (2004). Improvements in physical fitness in adults with down syndrome. American Journal on Mental Retardation, 104 (2), 165-174.

Rivas, M., \& Naranjo, J. R. (2007). Thyroid hormones, learning and memory. Genes, Brain and Behavior, 6, 4044.

Root, A.W., Shulman, D., Root, J., \& Diamond, F. (1986). The interrelationships of thyroid and growth hormones: effect of growth hormone releasing hormone in hypo- and hyperthyroid male rats. Acta Endocrinol Suppl, (279), 367-75.

Smail, K.M., \& Horvat, M. (2009). Clinician's corner: resistance training for individuals with intellectual disabilities. Clinical Kinesiology (Online), 63(2), 7.

Somashekar, A.R., Girish, V., Rao, C., \& Murthy, N.S. (2014). Correlation of cognitive performance and thyroid hormone levels in adolescents with subclinical hypothyroidism. Open Journal of Pediatrics, 4(02), 169.

Son, S., \& Jeon, B. (2017). Effects of an abdominal muscle exercise program in people with intellectual disabilities residing in a residential care facility. Journal of Physical Therapy Science, 29(7), 1196-1200.

Stavres, J.R., Zeigler, M.P., \& Bayles, M.P. (2018). Six weeks of moderate functional resistance training increases basal metabolic rate in sedentary adult women. Int J Exerc Sci, 11(2), 32-34.
Tirusew, (2005). Disability in Ethiopia: Issues, insights, and implications. Addis Ababa University Print.Press.

Tsolakis, C., \& Bogdanis, G.C. (2007). Influence of resistance training on anabolic hormones in prepubertal and pubertal males. Journal of Exercise Science and Physiology, 3(1), 1-11.

Weldeab, C.T., \& Opdal, L.R. (2007). Raising a child with intellectual disabilities in Ethiopia: What do parents say? Online Submission. The Annual Meeting of the American Educational Research Association Chicago, IL.

Wines, M. (2006). Malnutrition is cheating its survivors, and Africa's future. The New York Times, 28.

World Health Organization. (1996). Mental retardation division of health and prevention of substance abuse. International Classification of Diseases. $10^{\text {th }}$ Edition. ICD-10, Geneva.

World Health Organization. (2011). World report on disability 2011. World Health Organization.

Zenebe, K., Soumitra, M., Legesse, K., \& Abdulkader, M. (2019). Impacts of aerobic exercises on thyroid hormonal change responses of females' children with intellectual disabilities. Age (year) 4 (1), 1-88. 